\title{
Phylogenomic Analyses and Reclassification of Species within the Genus Tsukamurella: Insights to Species Definition in the Post-genomic Era
}

\section{OPEN ACCESS}

Edited by: Martin G. Klotz,

Queens College of the City University of New York, USA

Reviewed by:

Johannes F. Imhoff,

GEOMAR Helmholtz Centre for Ocean Research Kiel (HZ), Germany Brian Tindall,

German Collection of Microorganisms and Cell Cultures (LG), Germany

*Correspondence:

Susanna K. P. Lau skplau@hku.hk

Patrick C. Y. Woo

pcywoo@hkucc.hku.hk

tThese authors have contributed equally to this work.

Specialty section: This article was submitted to Evolutionary and Genomic Microbiology,

a section of the journal Frontiers in Microbiology

Received: 02 April 2016 Accepted: 07 July 2016

Published: 21 July 2016

Citation:

Teng JLL, Tang Y, Huang Y,

Guo F-B, Wei W, Chen JHK, Wong SSY, Lau SKP and Woo PCY (2016) Phylogenomic Analyses and Reclassification of Species within the

Genus Tsukamurella: Insights to Species Definition in the Post-genomic Era.

Front. Microbiol. 7:1137.

doi: 10.3389/fmicb.2016.01137
Jade L. L. Teng ${ }^{1,2,3,44}$, Ying Tang ${ }^{14}$, Yi Huang ${ }^{1}$, Feng-Biao Guo ${ }^{5}$, Wen Wei ${ }^{6}$, Jonathan H. K. Chen ${ }^{1}$, Samson S. Y. Wong ${ }^{1,2,3,4}$, Susanna K. P. Lau ${ }^{1,2,3,4,7 *}$ and Patrick C. Y. Woo ${ }^{1,2,3,4,7 *}$

${ }^{1}$ Department of Microbiology, The University of Hong Kong, Hong Kong, China, ${ }^{2}$ Research Centre of Infection and Immunology, The University of Hong Kong, Hong Kong, China, ${ }^{3}$ State Key Laboratory of Emerging Infectious Diseases, The University of Hong Kong, Hong Kong, China, ${ }^{4}$ Carol Yu Centre for Infection, The University of Hong Kong, Hong Kong, China, ${ }^{5}$ Centre of Bioinformatics, Key Laboratory for Neurolnformation of the Ministry of Education, School of Life Science and Technology, University of Electronic Science and Technology of China, Chengdu, China, ${ }^{6}$ School of Life Sciences, Chongqing University, Chongqing, China, ${ }^{7}$ Collaborative Innovation Center for Diagnosis and Treatment of Infectious Diseases, The University of Hong Kong, Hong Kong, China

Owing to the highly similar phenotypic profiles, protein spectra and 16S rRNA gene sequences observed between three pairs of Tsukamurella species (Tsukamurella pulmonis/Tsukamurella spongiae, Tsukamurella tyrosinosolvens/Tsukamurella carboxydivorans, and Tsukamurella pseudospumae/Tsukamurella sunchonensis), we hypothesize that and the six Tsukamurella species may have been misclassified and that there may only be three Tsukamurella species. In this study, we characterized the type strains of these six Tsukamurella species by tradition DNA-DNA hybridization $(\mathrm{DDH})$ and "digital DDH" after genome sequencing to determine their exact taxonomic positions. Traditional DDH showed $81.2 \pm 0.6 \%$ to $99.7 \pm 1.0 \%$ DNA-DNA relatedness between the two Tsukamurella species in each of the three pairs, which was above the threshold for same species designation. "Digital DDH" based on Genome-ToGenome Distance Calculator and Average Nucleotide Identity for the three pairs also showed similarity results in the range of 82.3-92.9 and 98.1-99.1\%, respectively, in line with results of traditional DDH. Based on these evidence and according to Rules $23 a$ and 42 of the Bacteriological Code, we propose that T. spongiae Olson et al. 2007, should be reclassified as a later heterotypic synonym of T. pulmonis Yassin et al. 1996, T. carboxydivorans Park et al. 2009, as a later heterotypic synonym of T. tyrosinosolvens Yassin et al. 1997, and T. sunchonensis Seong et al. 2008 as a later heterotypic synonym of T. pseudospumae Nam et al. 2004. With the advancement of genome sequencing technologies, classification of bacterial species can be readily achieved by "digital DDH" than traditional DDH.

Keywords: phylogenomic, reclassification, Tsukamurella, species, genomics 


\section{INTRODUCTION}

Traditionally, classification of bacteria is performed on the basis of their phenotypic characteristics, such as the appearance of the bacterium under light microscope after Gram staining, growth requirements, biochemical tests, and chemotaxonomic characteristics. However, the results of individual biochemical tests may vary among different strains of the same bacterial species, leading to variations in their biochemical profiles. Therefore, it is often difficult to determine whether a strain belongs to a new species or if it is just a variant of an existing species. In the 1970s, the discovery of conserved small ribosomal RNA (rRNA) gene sequences has marked the beginning of a new era for the study of evolution and classification of living organisms (Fox et al., 1977; Gupta et al., 1983). These rRNA gene sequences are, in general, highly conserved within living organisms of the same genus and species, but different between organisms of different genera and species. With the subsequent invention of PCR and automated DNA sequencing technology in the 1990s, 16S rRNA gene sequences have been widely used for phylogenetic, bacterial classification and identification. Numerous bacterial genera and species have been re-classified and renamed, and many novel bacterial genera and species have been discovered (Woo et al., 2008). However, careful analysis of $16 \mathrm{~S}$ rRNA data is needed to avoid misinterpretation of species classification, especially in cases where taxonomic claims are proposed on the basis of the $16 \mathrm{~S}$ rRNA data alone. For example, two strains that share $96 \% 16 \mathrm{~S}$ rRNA gene sequence similarity are determined to be members of different species; but in some cases, two strains that share $98 \% 16 \mathrm{~S}$ rRNA gene similarity may or may not be members of the same species (Stackebrandt and Goebel, 1994; Palys et al., 1997). As a result, it is difficult to use a universal cut-off value for classifying all bacteria to the species level. Other data sets should always be used in support of the claims.

In view of these problems, DNA-DNA hybridization (DDH) has remained the gold standard for classification in bacterial taxonomy. It represents a universally applicable technique that offers genome-wide comparisons between any bacteria, and a universal $\mathrm{DDH}$ value of $70 \%$ is proposed to be the criterion for bacterial species delineation (Wayne, 1988). However, this traditional method is time-consuming and labor-intensive, and it is difficult to compare DDH results between different laboratories objectively. Given these drawbacks, bacterial taxonomists have been actively searching for alternative methods to replace the traditional DDH for bacterial classification and species assignment (Goris et al., 2007). In the era of genomics, massive amounts of high-quality bacterial genome sequences can be easily obtained by high-throughput sequencing approach. As a result, different attempts have been made to replace the traditional wetlab DDH with in silico genome-to-genome comparison. Among the various "digital DDH" methods studied, the Genome-ToGenome Distance Calculator (GGDC) and Average Nucleotide Identity (ANI) calculator were shown to yield good correlation with wet-lab DDH values (Goris et al., 2007; Auch et al., 2010). GGDC operates on the same scale as the wet-lab DDH method and use the value of $70 \%$ as a cut-off for species delineation (Auch et al., 2010). ANI, on the other hand, estimates the average nucleotide identity between two genomic datasets, and an ANI value in the range of $94-96 \%$ has been suggested as the substitute for a wet-lab DDH value of 70\% (Konstantinidis and Tiedje, 2005; Goris et al., 2007; Richter and Rosselló-Móra, 2009).

The genus Tsukamurella was first proposed in 1988 by Collins and colleagues using both chemotaxonomic data and 16S rRNA gene sequence analysis (Collins et al., 1988), although taxonomic history of the genus can be dated back to 1941, when the first strain of this group of bacteria was isolated from mycetomes and ovaries of bed bugs (Cimex lectularius), and was initially named Corynebacterium paurometabolum (Steinhaus, 1941). Members of Tsukamurella are Gram-positive, aerobic, catalase-positive, and partially acid-fast, with morphology similar to the related genera of the order Actinomycetales, including Mycobacterium, Nocardia, Corynebacterium, Gordonia, and Rhodococcus. Chemotaxonomic characteristics, such as fatty acid, mycolic acid, menaquinone, and polar lipid composition, have been shown to be particularly useful to study the relatedness of actinomycete and coryneform systematics (Collins and Jones, 1982; Collins et al., 1982). At the time of writing, there are 13 species to be included in the genus Tsukamurella according to the current state of the taxonomy, with only seven species associated with human infections. The most common Tsukamurella infections in human are related to the presence of indwelling devices (Larkin et al., 1999; Shaer and Gadegbeku, 2001; Schwartz et al., 2002; Almehmi et al., 2004; Bouza et al., 2009; Liu et al., 2011). The disease spectra of Tsukamurella further extends to infections related to ophthalmologic diseases (Woo et al., 2003, 2009), and recently, we have reported the discovery of two novel Tsukamurella species, Tsukamurella hongkongensis and Tsukamurella sinensis, from patients with keratitis and conjunctivitis (Teng et al., 2015). Tsukamurella is also found in different environmental sources as well as in animals (Maeda et al., 2010; Jiang et al., 2013). However, as nucleotide differences between the 16S rRNA gene sequences of different Tsukamurella species are less than 1\% (Woo et al., 2003), defining a Tsukamurella strain as a novel species relies heavily on DDH results. However, it is important to note that DDH results may vary depending on the identity of the DNA used and any experimental problems cannot be checked in a different laboratory using the same samples, hence it is possible that Tsukamurella strains may be wrongly classified on the basis of DDH data alone.

During the process of characterization of $T$. hongkongensis and T. sinensis with other type strains of known Tsukamurella species, we observed that some of the known Tsukamurella species shared identical 16S rRNA gene sequence and highly similar phenotypic characteristics using the same testing method (Teng et al., 2015). Our results showed that almost identical phenotypic profiles were observed between Tsukamurella pulmonis CCUG $35732^{\mathrm{T}}$ (Yassin et al., 1996) and Tsukamurella spongiae DSM $44990^{\mathrm{T}}$ (Olson et al., 2007), between Tsukamurella tyrosinosolvens CCUG $38499^{\mathrm{T}}$ (Yassin et al., 1997) and Tsukamurella carboxydivorans JCM $15482^{\mathrm{T}}$ (Park et al., 2009), and between Tsukamurella pseudospumae JCM $13375^{\mathrm{T}}$ (Nam et al., 2004) and Tsukamurella sunchonensis JCM $15929^{\mathrm{T}}$ (Seong et al., 2003; Euzéby, 2008). However, 
phenotypic characteristics of these six Tsukamurella species obtained from our study were not comparable to those obtained from the original publications because different culture medium, reading interval and incubation conditions of the phenotypic tests have been applied in different studies (Yassin et al., 1996, 1997; Seong et al., 2003; Nam et al., 2004; Olson et al., 2007; Park et al., 2009). We further characterized these strains by matrix-assisted laser desorption ionization time-of-flight mass spectrometry (MALDI-TOF MS), in which the hierarchical cluster analysis dendrogram also revealed the same clustering patterns among these three pairs of Tsukamurella type strains. Therefore, we hypothesized that these six Tsukamurella species may have been misclassified and some of them may belong to the same Tsukamurella species. In fact, when some of these "novel" Tsukamurella species were described, only a marginal DDH result of around $62 \%$ was observed between T. tyrosinosolvens CCUG $38499^{\mathrm{T}}$ and T. carboxydivorans JCM $15482^{\mathrm{T}}$ (Park et al., 2009). In this study, we re-characterized these six Tsukamurella species by performing the traditional DDH again. In addition, we sequenced their genomes, which represented the first genomes to be sequenced for T. pulmonis, T. spongiae, T. tyrosinosolvens, T. carboxydivorans, T. pseudospumae, and T. sunchonensis, and performed "digital DDH" studies to determine their exact taxonomic positions using a phylogenomics approach.

\section{MATERIALS AND METHODS}

\section{Bacterial Strains}

The six strains included in this study were type strains and obtained from four culture collections, with T. pulmonis CCUG $35732^{\mathrm{T}}$ and T. tyrosinosolvens CCUG $38499^{\mathrm{T}}$ obtained from Culture Collection, University of Gothenburg, Sweden (CCUG), T. spongiae DSM $44990^{\mathrm{T}}$ from Leibniz Institute DSMZ-German Collection of Microorganisms and Cell Cultures, Germany (DSMZ), and T. sunchonensis JCM $15929^{\mathrm{T}}$, T. pseudospumae JCM $13375^{\mathrm{T}}$, and T. carboxydivorans JCM $15482^{\mathrm{T}}$ from Japan Collection of Microorganisms (JCM), Japan.

\section{Phenotypic Characterizations}

The six strains were phenotypically characterized in detail. Bacteria were streaked on Columbia agar with $5 \%$ defibrinated sheep blood and incubated at $25^{\circ} \mathrm{C}$ under aerobic condition for 2 days to observe the color of the colonies. Growth response to different temperatures $\left(25,37\right.$, and $\left.42^{\circ} \mathrm{C}\right)$ were determined by spreading bacterial cells of $0.5 \mathrm{McFarland}$ on Columbia agar with $5 \%$ defibrinated sheep blood agar followed by incubation under aerobic condition for up to 7 days. Hydrolysis of tyrosine and xanthine were tested as described previously (Conville and Witebsky, 2007). Biochemical data were obtained using the API $50 \mathrm{CH}$ systems (bioMérieux, France) at $25^{\circ} \mathrm{C}$ according to manufacturers' instructions. Reading intervals and durations of the tests followed the protocol suggested by Kattar et al. (2001). Cellular fatty acids were extracted directly from lyophilized cells (approximately $30 \mathrm{mg}$ of original wet weight) grown on Columbia agar with $5 \%$ defibrinated sheep blood at $25^{\circ} \mathrm{C}$ for 2 days and analyzed by gas chromatography as described by Microbial ID,
Inc. (Sasser, 1990) with peak-naming performed using MIDI, Inc. Sherlock Rapid Libraries and Methods.

\section{S rRNA Gene Sequencing}

The six strains were subjected to $16 \mathrm{~S}$ rRNA gene sequencing according to previously published protocol using primers LPW27807 (5' -TGGCTCAGGACGAACGCT-3') and LPW27808 (5'-GAGGTGATCCAGCCGCA-3'; Teng et al., 2015). The sequences of PCR products were compared to known gene sequences in GenBank by multiple sequence alignment using Bioedit 7.1.9 (Hall, 1999). Phylogenetic tree was constructed by maximum likelihood method using the model GTR + I + G in MEGA 6.0 (Tamura et al., 2013).

\section{MALDI-TOF MS Analysis}

MALDI-TOF MS of all Tsukamurella strains was performed as previously described (Verroken et al., 2010; Lau et al., 2014; Teng et al., 2014) with slight modifications. Briefly, bacteria were first grown aerobically on horse blood agar at $37^{\circ} \mathrm{C}$ for 2 days. Two to three colonies were scraped in $500 \mu \mathrm{l}$ of distilled water and boiled for $30 \mathrm{~min}$. After centrifugation at 13,000 rpm for $2 \mathrm{~min}, 300 \mu \mathrm{l}$ of water followed by $900 \mu \mathrm{l}$ of $100 \%$ ethanol was added and centrifuged at 13,000 rpm for 2 min twice. Supernatant was removed and pellet was air dried thoroughly. Fifty microliters of $70 \%$ formic acid was then added and mixed well with the pellet at room temperature for $15 \mathrm{~min}$. Finally the solution was mixed with $50 \mu \mathrm{l}$ of acetonitrile and centrifuged at $13,000 \mathrm{rpm}$ for $2 \mathrm{~min}$. One microliter of supernatant was loaded to a 96-well-spot polished steel target plate (Bruker Daltonik, Bremen, Germany) and air dried. One microliter of matrix solution ( $\alpha$-cyano-4-hydroxycinnamic acid; Sigma Aldrich, St Louis, USA) was applied and allowed to air dry. Within the range of $m / z 2,000-20,000 \mathrm{Da}$, spectra were obtained with an accelerating voltage of $20 \mathrm{kV}$ and collected in linear mode using the MicroFlex LT (Bruker Daltonik). Resulting data was analyzed with MALDI Biotyper 3.1 and a score of $\geq 1.7$ and $\geq 2.0$, as determined by the Reference Library V.3.1.2.0. Bruker Biotyper, was considered to be confident for identification on the genus and species level, respectively. Main spectral pattern (MSP) created from representative spectra of each strain were selected for hierarchical cluster analysis using the Bruker Biotyper software with default parameters (Ketterlinus et al., 2005).

\section{Wet-Lab DNA-DNA Hybridization}

$\mathrm{DDH}$ studies were performed between T. pulmonis CCUG $35732^{\mathrm{T}}$ and $T$. spongiae DSM $44990^{\mathrm{T}}$, T. tyrosinosolvens CCUG $38499^{\mathrm{T}}$ and T. carboxydivorans JCM $15482^{\mathrm{T}}$ and T. pseudospumae JCM $13375^{\mathrm{T}}$ and T. sunchonensis JCM $15929^{\mathrm{T}}$, respectively. Preparation of genomic DNA was performed using QIAGEN Genomic tip 100-G (Qiagen, Hilden, Germany). DNA probe was prepared using reagent DIG-High Prime DNA labeling (Roche Diagnostics, Basel, Switzerland) according to Seong et al. (2003), while DNA-DNA dot blot hybridization was carried out using ULTRAhyb ultrasensitive hybridization buffer (Ambion, New York, USA), DIG wash and block buffers, anti-DIG-AP and CDP-Star (Roche Diagnostics) as described previously (Woo et al., 2014; Teng et al., 2015). DDH was performed at $42^{\circ} \mathrm{C}$ in 
triplicate for each of the probe used. To quantify the relative levels of DNA-DNA relatedness, developed X-ray films were scanned and dot intensities were analyzed using the software ImageJ 1.46r (Abràmoff et al., 2004). Self-hybridization values were considered to be $100 \%$, representing the maximal achievable signal. Values obtained with other test strains were compared with this standard (Woo et al., 2014; Teng et al., 2015). Reciprocal hybridizations were also performed.

\section{Genome Sequencing, Assembly, and Annotation of the Six Tsukamurella Species}

The draft genome sequences of the six Tsukamurella species were determined by high-throughput sequencing with Illumina Hi-Seq 2500. Genomic DNA of each strain was extracted from overnight cultures $\left(37^{\circ} \mathrm{C}\right)$ grown on blood agars using the genomic DNA purification kit (Qiagen) as described previously (Woo et al., 2009; Tse et al., 2010). Extracted DNA was then sequenced by 151-bp paired-end reads with mean library size of $350 \mathrm{bp}$. Sequencing errors were corrected by k-mer frequency spectrum analysis using $\mathrm{SOAPec}^{1}$. De novo assembly was performed using SOAPdenovo $2^{2}$. Prediction of protein coding regions and automatic functional annotation was performed using RAST (Rapid Annotations using Subsystem Technology) server version $2.0^{3}$ (Delcher et al., 2007; Aziz et al., 2008). Genomic islands were predicted by Zisland Explorer method ${ }^{4}$ (Wei and Guo, 2011; Wei et al., 2016).

\section{Phylogenomic Characterizations}

The phylogenetic tree based on entire genome sequences was constructed by neighbor-joining method using GGDC distance (formula 2) and Dietzia cinnamea (NZ_AEKG01000298.1) as the root. The tree was saved in Newick format and subsequently processed by MEGA (Tamura et al., 2013). Intergenomic distance between these six Tsukamurella species was calculated using GGDC $2.1^{5}$ and ANI $^{6}$ (Goris et al., 2007; Auch et al., 2010). The web service can be used for calculating intergenomic distances, with 70\% (GGDC) and 94-96\% (ANI) as the substitute for a wet-lab DDH value of $70 \%$ for same species delineation.

\section{RESULTS AND DISCUSSION}

\section{Phenotypic Characteristics}

The biochemical and physiological properties of T. pulmonis CCUG $35732^{\mathrm{T}}$, T. spongiae DSM $44990^{\mathrm{T}}$, T. tyrosinosolvens CCUG $38499^{\mathrm{T}}$, T. carboxydivorans JCM $15482^{\mathrm{T}}$, T. pseudospumae JCM $13375^{\mathrm{T}}$, and T. sunchonensis JCM $15929^{\mathrm{T}}$ and are summarized in Table 1. Of the six Tsukamurella

\footnotetext{
${ }^{1}$ http://soap.genomics.org.cn/about.html

${ }^{2}$ http://soap.genomics.org.cn/

${ }^{3}$ http://rast.nmpdr.org/rast.cgi

${ }^{4} \mathrm{http}: / /$ cefg.uestc.edu.cn/Zisland_Explorer/

${ }^{5}$ http://ggdc.dsmz.de/distcalc2.php

${ }^{6} \mathrm{http}: / /$ enve-omics.ce.gatech.edu/ani/
}

species, all were aerobic, non-sporulating, Gram-positive bacilli, and grew on sheep blood agar as white or orange to red colonies of $<5 \mathrm{~mm}$ in diameter after $48 \mathrm{~h}$ of incubation at $25^{\circ} \mathrm{C}$ in ambient air. All of them grew well at 25 and $37^{\circ} \mathrm{C}$ but none of them grew at $42^{\circ} \mathrm{C}$. T. tyrosinosolvens CCUG $38499^{\mathrm{T}}$, T. carboxydivorans JCM $15482^{\mathrm{T}}$, T. pseudospumae JCM $13375^{\mathrm{T}}$, and T. sunchonensis JCM $15929^{\mathrm{T}}$ could hydrolyse tyrosine but only $T$. carboxydivorans JCM $15482^{\mathrm{T}}$ could hydrolyse xanthine. Sugar assimilation results using API $50 \mathrm{CH}$ systems (bioMérieux, France) showed almost identical phenotypic profiles between T. pulmonis CCUG $35732^{\mathrm{T}}$ and T. spongiae DSM $44990^{\mathrm{T}}$ (48 of 49 sugar assimilation results were identical), between T. tyrosinosolvens CCUG $38499^{\mathrm{T}}$ and T. carboxydivorans JCM $15482^{\mathrm{T}}$ (48 of 49 sugar assimilation results were identical), and between T. pseudospumae JCM $13375^{\mathrm{T}}$ and T. sunchonensis JCM $15929^{\mathrm{T}}$ (45 of 49 sugar assimilation results were identical). The fatty acid profiles of the six Tsukamurella species are summarized in Table 2. The major fatty acids compositions of strains T. pulmonis CCUG $35732^{\mathrm{T}}$, T. spongiae DSM $44990^{\mathrm{T}}$, T. tyrosinosolvens CCUG $38499^{\mathrm{T}}, T$. carboxydivorans JCM $15482^{\mathrm{T}}$, T. pseudospumae JCM $13375^{\mathrm{T}}$, and T. sunchonensis JCM $15929^{\mathrm{T}}$ included $\mathrm{C}_{16: 0}, \mathrm{C}_{18: 1 \omega 9 c}$, and 10-methyl $\mathrm{C}_{18: 0}$, which is typical of members of Tsukamurella (Table 2; Goodfellow and Kumar, 2012).

\section{S rRNA Gene Sequencing}

Sequencing of the 16S rRNA gene of the six Tsukamurella species showed that there were 5-56 (0.3-3.8\%) base differences between their 16S rRNA gene sequences and those of the type strains of other currently recognized Tsukamurella species. Pairwise sequence similarity calculations showed identical 16S rRNA gene sequences between T. pulmonis CCUG $35732^{\mathrm{T}}$ and T. spongiae DSM $44990^{\mathrm{T}}$, between T. tyrosinosolvens CCUG $38499^{\mathrm{T}}$ and T. carboxydivorans JCM $15482^{\mathrm{T}}$, and between T. pseudospumae JCM $13375^{\mathrm{T}}$ and T. sunchonensis JCM $15929^{\mathrm{T}}$ (Figure 1).

\section{MALDI-TOF MS Analysis}

Consistent with the results of phenotypic characterization, dendrogram generated from hierarchical cluster analysis of MALDI-TOF MS showed that the spectra of these six Tsukamurella species and the representatives of the only two Tsukamurella species, Tsukamurella inchonensis and Tsukamurella paurometabola, available in the Bruker reference library revealed the same clustering pattern (Figure 2). Specifically, same cluster was observed between T. pulmonis CCUG $35732^{\mathrm{T}}$ and T. spongiae DSM $44990^{\mathrm{T}}$, between $T$. tyrosinosolvens CCUG $38499^{\mathrm{T}}$ and $T$. carboxydivorans JCM $15482^{\mathrm{T}}$, and between T. pseudospumae JCM $13375^{\mathrm{T}}$ and T. sunchonensis JCM $15929^{\mathrm{T}}$ (Figure 2).

\section{Wet-lab DNA-DNA Hybridization}

Using the DDH, we found that DNA-DNA relatedness between T. pulmonis CCUG $35732^{\mathrm{T}}$ and T. spongiae DSM $44990^{\mathrm{T}}$, T. tyrosinosolvens CCUG $38499^{\mathrm{T}}$ and $T$. carboxydivorans JCM $15482^{\mathrm{T}}$, and T. pseudospumae JCM $13375^{\mathrm{T}}$ and T. sunchonensis JCM $15929^{\mathrm{T}}$ were demonstrated to be $>70 \%$, respectively. T. pulmonis CCUG $35732^{\mathrm{T}}$ and T. spongiae DSM $44990^{\mathrm{T}}$ 
TABLE 1 | Phenotypic properties of T. pulmonis CCUG $35732^{\top}$, T. spongiae DSM $44990^{\top}$, T. tyrosinosolvens CCUG $38499^{\top}$, T. carboxydivorans JCM $15482^{\top}$, T. pseudospumae $\mathrm{JCM} 13375^{\top}$, and T. sunchonensis $\mathrm{JCM} 15929^{\top}$.

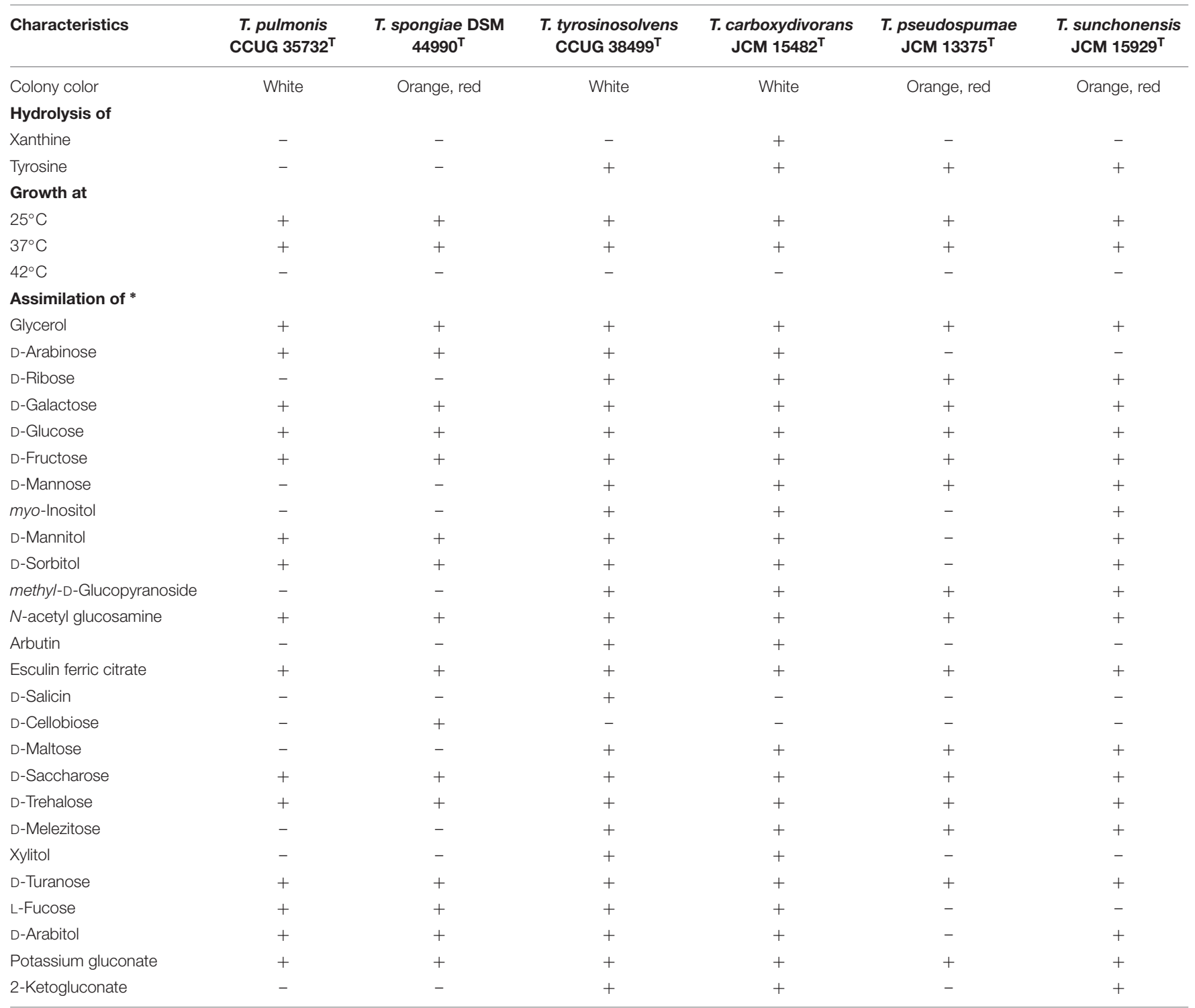

*Negative results in all six isolates were not shown in this table. All results are obtained from this study.

possessed $91.1 \pm 3.9 \%$ (mean $\pm \mathrm{SD}, n=3$, T. pulmonis CCUG $35732^{\mathrm{T}}$ as probe) or $84.2 \pm 3.2 \%$ DNA-DNA relatedness (mean $\pm \mathrm{SD}, n=3$, T. spongiae $\mathrm{DSM} 44990^{\mathrm{T}}$ as probe). $T$. tyrosinosolvens CCUG $38499^{\mathrm{T}}$ and $T$. carboxydivorans JCM $15482^{\mathrm{T}}$ possessed $90.5 \pm 1.3 \%$ (mean $\pm \mathrm{SD}, n=3$, T. tyrosinosolvens CCUG $38499^{\mathrm{T}}$ as probe) or $81.2 \pm 0.6 \%$ DNA-DNA relatedness (mean $\pm \mathrm{SD}, n=3$, T. carboxydivorans JCM $15482^{\mathrm{T}}$ as probe). T. pseudospumae JCM $13375^{\mathrm{T}}$ and T. sunchonensis JCM $15929^{\mathrm{T}}$ possessed $95.1 \pm 4.9 \%$ DNADNA relatedness (mean $\pm \mathrm{SD}, n=3, T$. pseudospumae JCM $13375^{\mathrm{T}}$ as probe) or $99.7 \pm 1.0 \%$ (mean $\pm \mathrm{SD}, n=3$, T. sunchonensis JCM $15929^{\mathrm{T}}$ as probe). According to the criterion for species delineation using DDH, the present results $(>70 \%$ $\mathrm{DDH}$ ) suggested that these six Tsukamurella species should be reclassified as three distinct species. It is worth noting though, that the present DDH values are different from those obtained in the previous studies, in which the DNA-DNA relatedness between T. pulmonis CCUG $35732^{\mathrm{T}}$ and T. spongiae DSM $44990^{\mathrm{T}}$ was $48.0 \pm 1.3 \%$ (mean $\pm \mathrm{SD}, n=3$, T. spongiae DSM $44990^{\mathrm{T}}$ as probe; Olson et al., 2007) and that of T. tyrosinosolvens CCUG $38499^{\mathrm{T}}$ and T. carboxydivorans JCM $15482^{\mathrm{T}}$ was $62.7 \pm 3.4 \%$ (mean $\pm \mathrm{SD}, n=3$, T. carboxydivorans $\mathrm{JCM} 15482^{\mathrm{T}}$ as probe; Park et al., 2009). To further verify our results, we sequenced the genomes of these six Tsukamurella species for accurate species classification.

\section{General Features of the Genomes}

We sequenced the first draft genomes of the type strains of the six Tsukamurella species using high-throughput sequencing to investigate their genetic relatedness and to confirm their taxonomic positions. Sequencing generated 2.12 million 
TABLE 2 | Fatty acid compositions (\%) of T. pulmonis CCUG $35732^{\top}$, T. spongiae DSM $44990^{\top}$, T. tyrosinosolvens CCUG $38499^{\top}$, T. carboxydivorans JCM $15482^{\top}$, T. pseudospumae $\mathrm{JCM} 13375^{\top}$, and T. sunchonensis $\mathrm{JCM} 15929^{\top}$.

\begin{tabular}{|c|c|c|c|c|c|c|}
\hline & $\begin{array}{l}\text { T. pulmonis } \\
{\text { CCUG } 35732^{\top}}^{\top}\end{array}$ & $\begin{array}{c}\text { T. spongiae DSM } \\
44990^{\top}\end{array}$ & $\begin{array}{l}\text { T. tyrosinosolvens } \\
\text { CCUG } 38499^{\top}\end{array}$ & $\begin{array}{l}\text { T. carboxydivorans } \\
\text { JCM } 15482^{\top}\end{array}$ & $\begin{array}{l}\text { T. pseudospumae } \\
\text { JCM } 13375^{\top}\end{array}$ & $\begin{array}{l}\text { T. sunchonensis } \\
\text { JCM } 15929^{\top}\end{array}$ \\
\hline $\mathrm{C}_{14: 0}$ & 4.0 & 3.4 & 4.1 & 3.9 & 4.1 & 2.5 \\
\hline$C_{16: 0}$ & 22.6 & 22.1 & 23.0 & 25.1 & 26.4 & 25.4 \\
\hline $\mathrm{C}_{17: 1 \omega 8 \mathrm{C}}$ & - & - & 1.2 & 1.2 & - & - \\
\hline $\mathrm{C}_{17: 0}$ & - & - & 1.0 & 1.5 & - & - \\
\hline 10-methyl $C_{18: 0}$ & 10.7 & 10.0 & 13.4 & 10.8 & 10.9 & 21.0 \\
\hline $\mathrm{C}_{20: 1 \omega 9 \mathrm{c}}$ & 3.3 & 1.1 & 1.8 & 2.0 & 1.6 & 1.2 \\
\hline SF1 & 15.2 & 19.5 & 16.4 & 15.2 & 15.6 & 16.2 \\
\hline
\end{tabular}

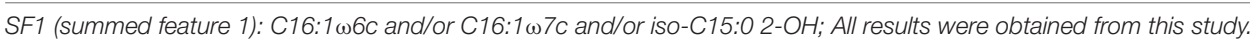

- , Less than $1 \%$ or not detected.

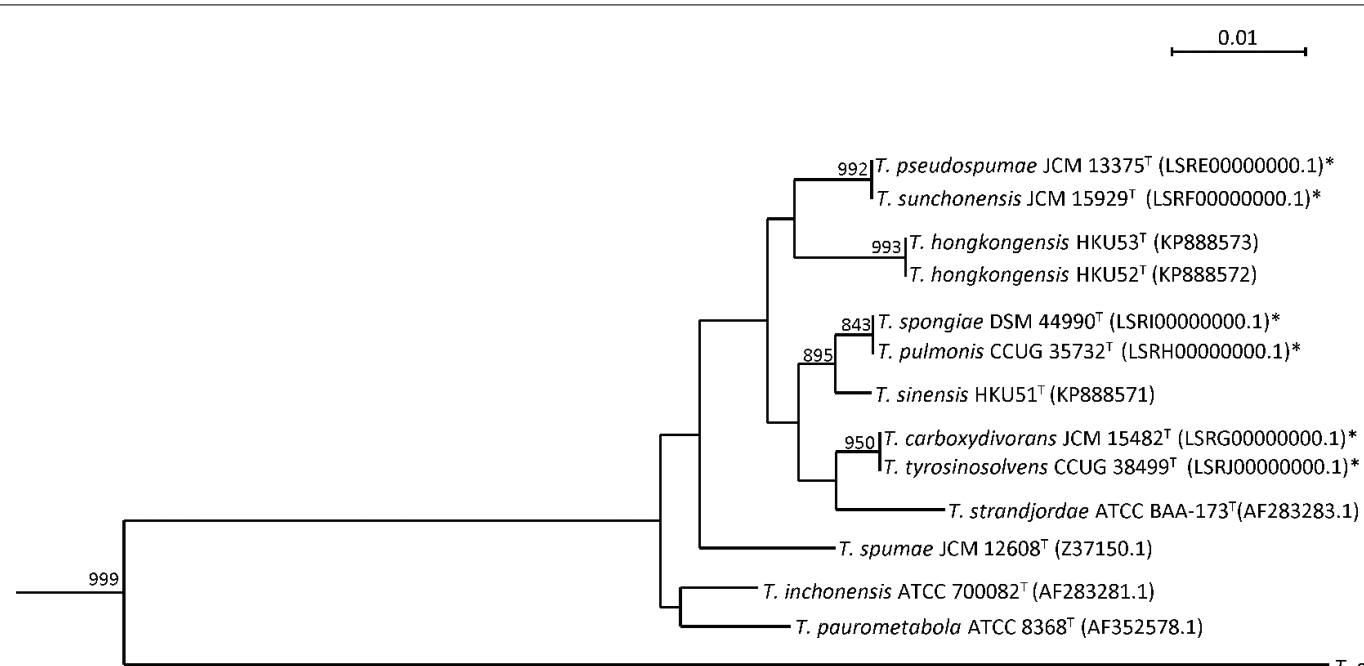

T. soli JCM 17688T (FJ917743.2)

FIGURE 1 | Phylogenetic tree showing the relationship of Tsukamurella species using 16S rRNA gene sequence analysis. The tree was constructed by maximum likelihood method using D. cinnamea (NZ_AEKG01000298.1) as the root. A total of 1407 nucleotide positions were included in the analysis. Bootstrap values were calculated from 1000 replicates. The scale bar indicates the number of substitutions per site. Names and accession numbers are given as cited in GenBank database. Sequences that were obtained in this study are marked by an asterisk.

TABLE 3 | Results of draft genome assembly of the six Tsukamurella species.

\begin{tabular}{|c|c|c|c|c|c|c|}
\hline $\begin{array}{l}\text { Genome assembly } \\
\text { data }\end{array}$ & $\begin{array}{c}\text { T. pulmonis CCUG } \\
3_{35732^{\top}}\end{array}$ & $\begin{array}{c}\text { T. spongiae DSM } \\
44990^{\top}\end{array}$ & $\begin{array}{l}\text { T. tyrosinosolvens } \\
\text { CCUG } 38499^{\top}\end{array}$ & $\begin{array}{l}\text { T. carboxydivorans } \\
\text { JCM } 15482^{\top}\end{array}$ & $\begin{array}{l}\text { T. pseudospumae } \\
\text { JCM } 13375^{\top}\end{array}$ & $\begin{array}{l}\text { T. sunchonensis } \\
\text { JCM } 15929^{\top}\end{array}$ \\
\hline Genome size (Mb) & 4.74 & 4.60 & 5.23 & 4.95 & 4.95 & 5.21 \\
\hline No. of contigs & 62 & 51 & 73 & 29 & 70 & 133 \\
\hline $\begin{array}{l}\text { No. of predicted } \\
\text { protein-coding genes }\end{array}$ & 4,538 & 4,412 & 5,191 & 4,709 & 4,823 & 5,050 \\
\hline
\end{tabular}

paired-end reads per strain (estimated $80 \times$ coverage). After de novo assembly, the six draft genomes ranged from 4.6 to $5.2 \mathrm{Mb}$ in length $(\mathrm{G}+\mathrm{C}$ content $70.4-71.2 \%)$ distributed in 18-74 large contigs ( $>500$ bp; GenBank accession numbers LSRE01000000-LSRJ01000000). All contigs generated for each strain were submitted to the RAST version 2.0 annotation server respectively, resulting in 4,412-5,191 protein-coding sequences (CDSs; Table 3). To facilitate the subsequent genomic analysis, genome sequences of T. paurometabola DSM $20162^{\mathrm{T}}$ (GenBank accession number NC_014158.1) and "T. algeriensis" 1534 (GenBank accession number NZ_HE997626.1), the only two available genome sequences in GenBank, were also 


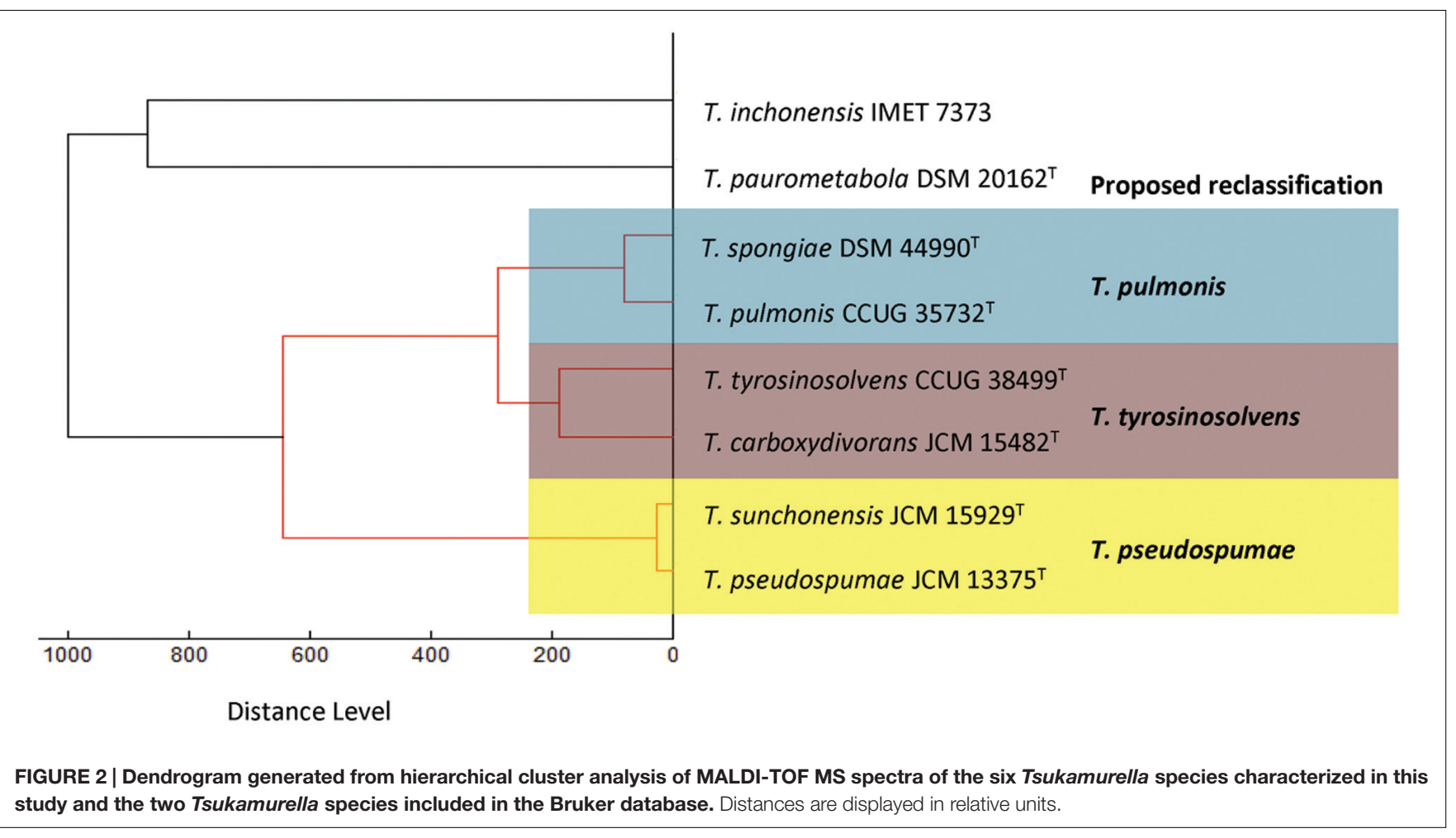

submitted to RAST for annotation. Each CDS in annotated genomes was grouped into different RAST subsystems based on the predicted functional role. Among the 4,412-5,191 CDS in these six draft genomes, only 1,629-1,762 CDSs can be categorized into RAST systems, representing $34-38 \%$ of total CDSs. Overall, the majority of CDSs were classified into subsystems of amino acid and derivatives (444-490 CDSs, 16.9-18.1\%), carbohydrates (297-380 CDSs, 11.7-13.5\%), cofactors, vitamins, prosthetic groups, pigments (294-335 CDSs, 11.4-11.9\%) and protein metabolism (255-271 CDSs, 9.2-10.2\%). The remaining 2,783-3,452 (62-66\%) CDSs could not be classified into any subsystems, in which 1,450-1,720 (31.6-34.6\%) CDSs were only annotated as hypothetical proteins. When we compared the distribution of CDSs in each subsystem of these six Tsukamurella genomes with those of T. paurometabola and "T. algeriensis" genomes, all of them have a similar percentage of their genome dedicated to each subsystem (Figure 3).

\section{Phylogenomic Analyses of the Six Tsukamurella Species}

With the availability of these six Tsukamurella genome sequences, as well as the genome sequences of T. paurometabola DSM $20162^{\mathrm{T}}$ and " $T$. algeriensis" 1534 from GenBank, we used two independent "digital DDH" methods, GGDC and ANI, to estimate the overall similarity between the genomes of two strains, which in turn determined the genome-based species delineation among these six Tsukamurella species. Consistent with the results obtained by traditional $\mathrm{DDH}$, in silico genome-togenome comparison unambiguously showed that for T. pulmonis
CCUG $35732^{\mathrm{T}}$ and T. spongiae DSM $44990^{\mathrm{T}}$, T. tyrosinosolvens CCUG $38499^{\mathrm{T}}$ and $T$. carboxydivorans JCM $15482^{\mathrm{T}}$, and T. pseudospumae JCM $13375^{\mathrm{T}}$ and T. sunchonensis JCM $15929^{\mathrm{T}}$, GGDC and ANI values for more than 70 and 94-96\%, respectively were observed (Table 4). As these calculated values are above the threshold for same species designation, it was suggested that the current six Tsukamurella species should be reclassified as only three distinct Tsukamurella species.

The proposed reclassification is also supported by the phylogenomic analyses (Figure 4) and whole genome sequence comparison (Figure 5) using the draft genome sequences of the six Tsukamurella species. The phylogenetic tree constructed using the draft genomes sequences (Figure 4) was concordant to the clustering pattern as observed in phenotypic (Table 1) and MALDI-TOF MS analyses (Figure 2). As for genome sequence comparison, high protein sequence identities ( $>90 \%$ as indicated by blue color) were observed in each orthologous gene between the genomes of T. pulmonis CCUG $35732^{\mathrm{T}}$ and T. spongiae DSM $44990^{\mathrm{T}}$ (Figure 5A), between the genomes of T. tyrosinosolvens CCUG $38499^{\mathrm{T}}$ and T. carboxydivorans JCM $15482^{\mathrm{T}}$ (Figure 5B), and between the genomes of T. pseudospumae JCM $13375^{\mathrm{T}}$ and T. sunchonensis JCM $15929^{\mathrm{T}}$ (Figure 5C). Interestingly, although relatively high sequence similarity was observed between the genomes of T. tyrosinosolvens CCUG $38499^{\mathrm{T}}$ and T. carboxydivorans $\mathrm{JCM} 15482^{\mathrm{T}}$, some regions were found to be uniquely present in the type strain of $T$. tyrosinosolvens only. These unique regions are likely to be genomic islands as predicted by Zisland Explorer method (Figure 5B). RAST analysis showed that most of the ORFs within these putative genomic islands were annotated as hypothetic proteins, phage 


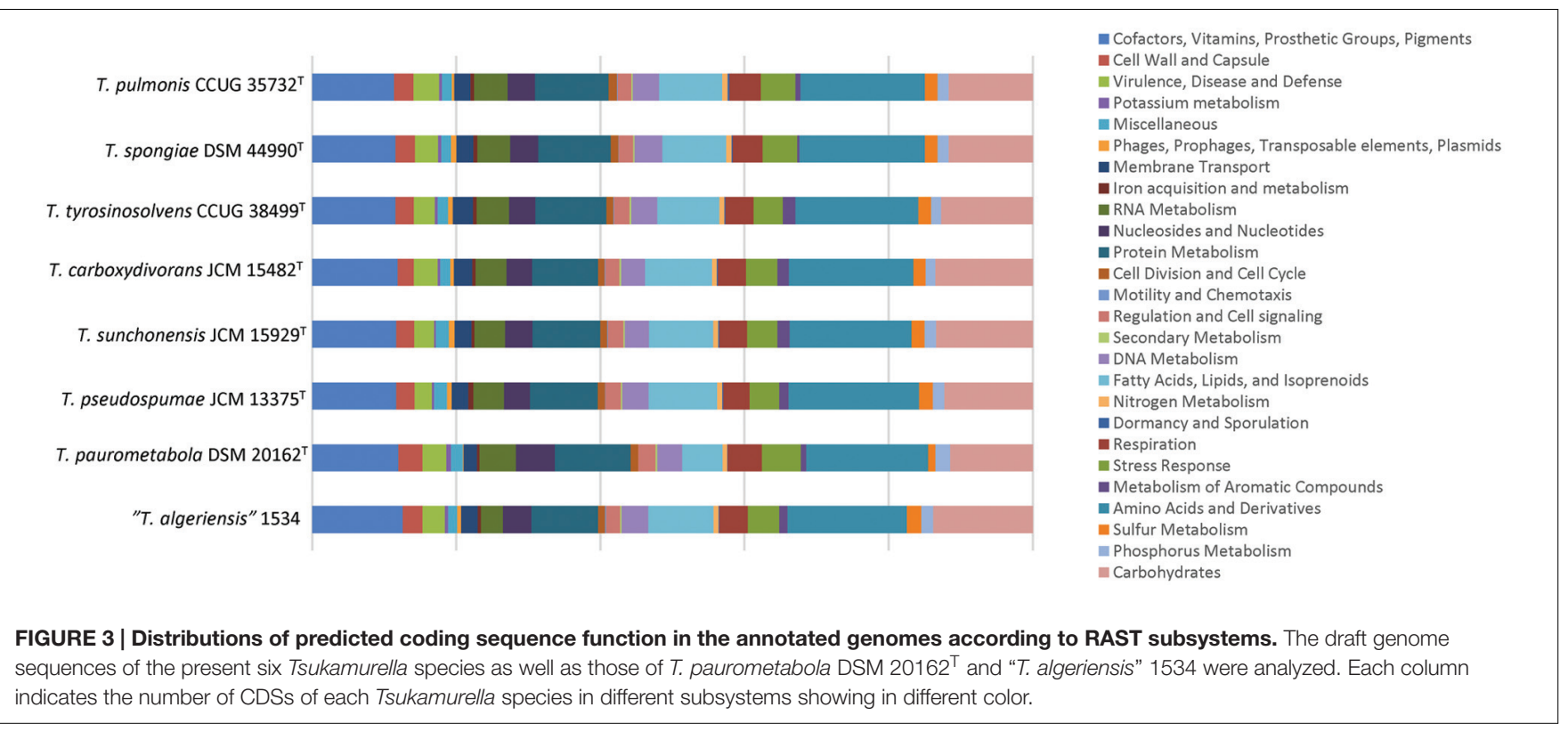

TABLE 4 | Intergenomic distance between the draft genomes of the six currently recognized Tsukamurella species represented by ANI (upper triangle) and GGDC (lower triangle) values (\%).

\begin{tabular}{|c|c|c|c|c|c|c|}
\hline Strains & $\begin{array}{l}\text { T. pulmonis } \\
\text { CCUG } 35732^{\top}\end{array}$ & $\begin{array}{c}\text { T. spongiae DSM } \\
44990^{\top}\end{array}$ & $\begin{array}{l}\text { T. tyrosinosolvens } \\
\text { CCUG } 38499^{\top}\end{array}$ & $\begin{array}{l}\text { T. carboxydivorans } \\
\text { JCM } 15482^{\top}\end{array}$ & $\begin{array}{l}\text { T. pseudospumae } \\
\text { JCM } 13375^{\top}\end{array}$ & $\begin{array}{l}\text { T. sunchonensis } \\
\text { JCM } 15929^{\top}\end{array}$ \\
\hline T. pulmonis CCUG $35732^{\top}$ & - & 99.1 & 87.3 & 87.2 & 84.6 & 84.8 \\
\hline T. tyrosinosolvens CCUG $38499^{\top}$ & 34.3 & 34.3 & - & 98.8 & 85.1 & 85.1 \\
\hline T. carboxydivorans JCM $15482^{\top}$ & 34.0 & 33.9 & 90.4 & - & 85.0 & 84.8 \\
\hline T. pseudospumae JCM $13375^{\top}$ & 28.4 & 28.4 & 29.4 & 29.4 & - & 98.1 \\
\hline
\end{tabular}

Species with > 70\% GGDC and >94-96\% ANI values, suggesting same species delineation, are bolded.

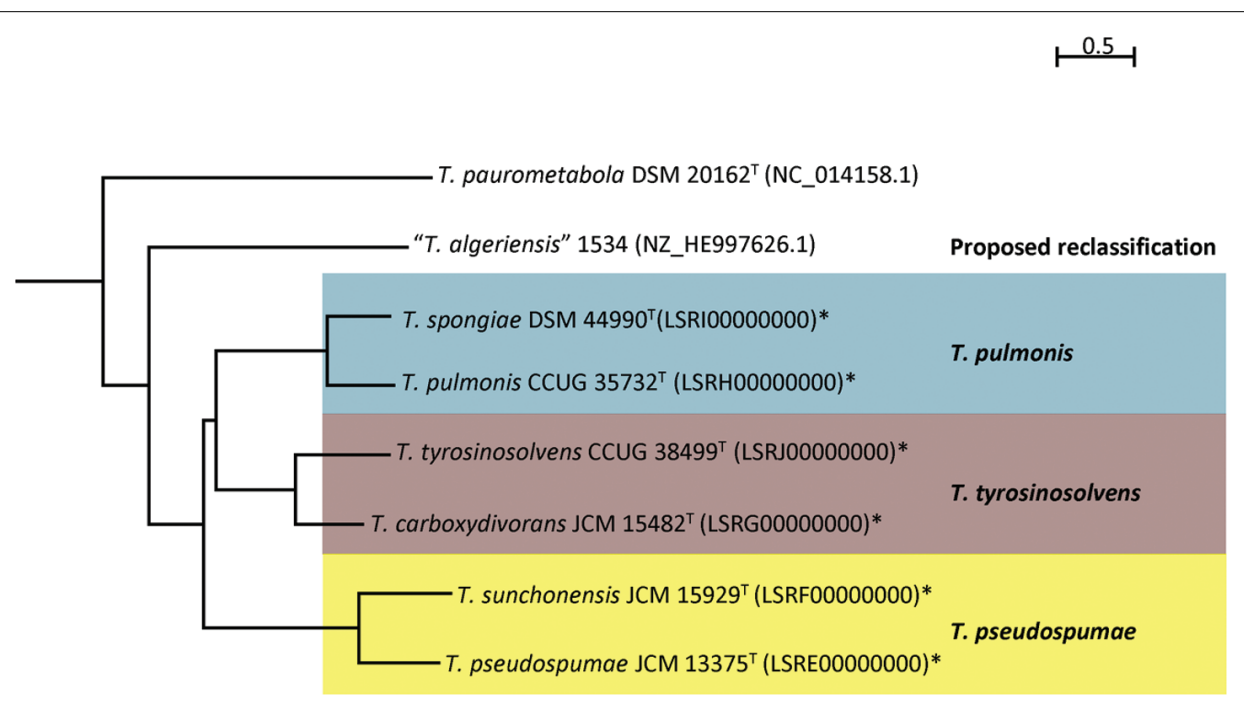

FIGURE 4 | Phylogenetic relationship among Tsukamurella strains with genome sequence available. Neighbor-joining tree constructed on the basis of draft genome sequences GGDC distance (formula 2) and D. cinnamea (NZ_AEKG01000298.1) as the root. Scale bar indicates mean number of nucleotide substitutions per site on the respective branch. Names and accession numbers are given as cited in GenBank. Sequences that were obtained in this study are marked by an asterisk. 

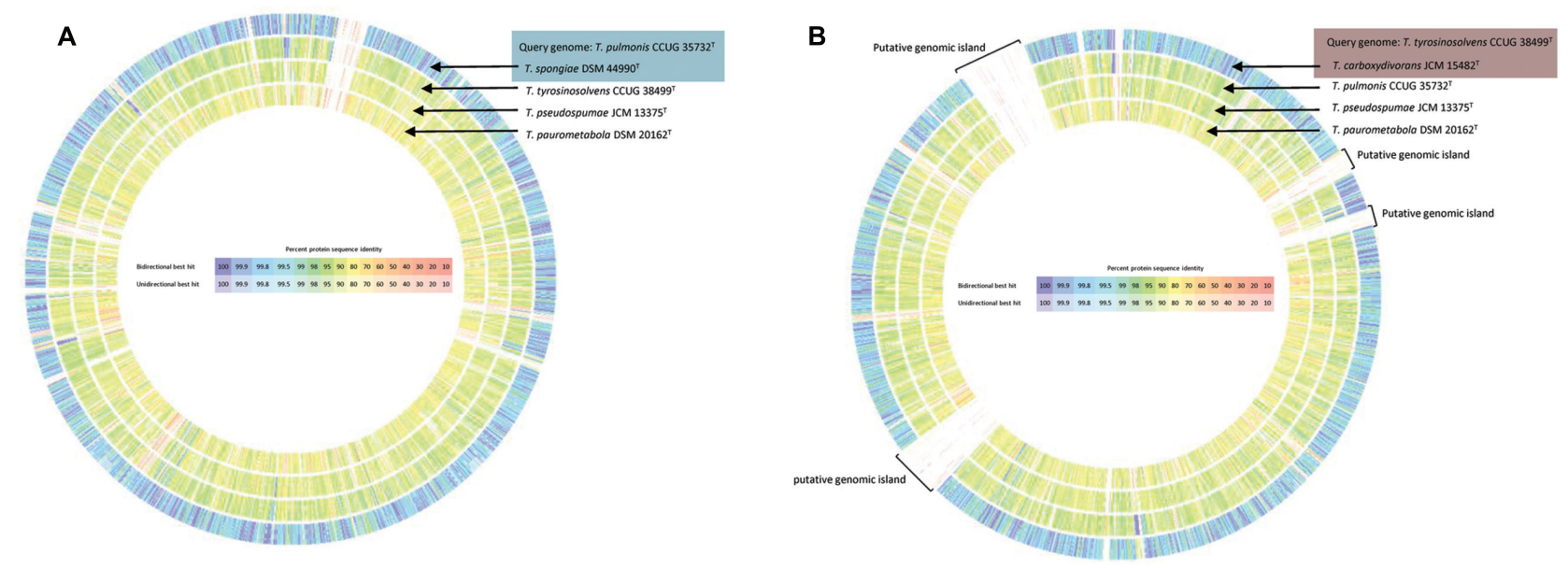

C

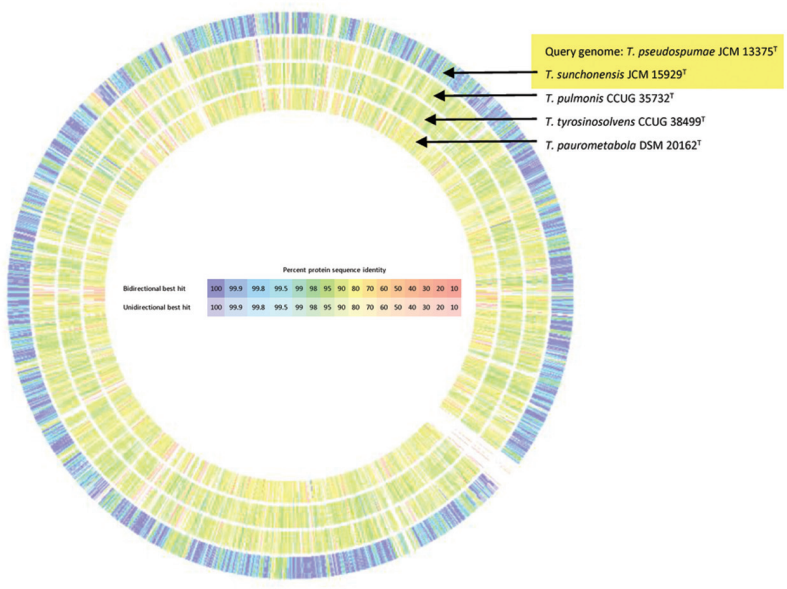

FIGURE 5 | Circular representation of the genome comparison between the draft genomes of the present study and that of $T$. paurometabola DSM 20162 ${ }^{\top}$ (NC_014158.1). T. pulmonis CCUG $35732^{\top}$ (A), T. tyrosinosolvens CCUG $38499^{\top}$ (B), and T. pseudospumae JCM $13375^{\top}$ (C) were used as query genome, respectively and compared with other selected bacterial genomes as indicated. Comparison was generated in RAST. Intensity of color indicates degree of protein identity, with blue to purple color indicating higher protein identity. Tsukamurella species with majority of orthologous genes sharing high protein identities to the query species was shaded using the same color.

related proteins and mobile element proteins. As the type strain of T. tyrosinosolvens was isolated from blood culture of a patient with cardiac pacemaker implants, whereas $T$. carboxydivorans JCM $15482^{\mathrm{T}}$ was isolated from soil, the pathogenic role of these genomic islands warrants further investigations. Given all genomic evidence, T. spongiae DSM $44990^{\mathrm{T}}$, T. carboxydivorans JCM $15482^{\mathrm{T}}$, and T. sunchonensis JCM $15929^{\mathrm{T}}$ likely represent previously misclassified isolates that actually belong to the same species of T. pulmonis, T. tyrosinosolvens, and T. sunchonensis, respectively. According to Rules $23 \mathrm{a}$ and 42 of the Bacteriological Code (Lapage et al., 1992), we propose that T. spongiae Olson et al. 2007 (Olson et al., 2007), T. carboxydivorans Park et al. 2009 (Park et al., 2009), and T. sunchonensis Seong et al. 2008 (Seong et al., 2003) should be reclassified as later heterotypic synonyms of T. pulmonis Yassin et al. 1996 (Yassin et al., 1996), T. tyrosinosolvens Yassin et al. 1997 (Yassin et al., 1997), and T. pseudospumae Nam et al. 2004 (Nam et al., 2004), respectively.

\section{PROPOSAL FOR A RECLASSIFICATION OF SPECIES WITHIN THE GENUS TSUKAMURELLA}

In this study, we sequenced the first draft genomes of six Tsukamurella species and unambiguously determined their phylogenetic positions using a phylogenomics approach. Consistent with the results of $16 \mathrm{~S}$ rRNA gene sequencing, phenotypic and MALDI-TOF MS analyses, additional genomic evidences, including intergenomic distance comparisons using GGDC and ANI, phylogenetic analysis and whole genome comparison based on the draft genomes, support that the currently recognized six Tsukamurella species should be reclassified as three species only. According to Rules 23a and 42 of the Bacteriological Code (Lapage et al., 1992), it is proposed that T. spongiae Olson et al. 2007 (Olson et al., 2007) should be reclassified as a later heterotypic synonym of $T$. pulmonis 
Yassin et al. 1996 (Yassin et al., 1996), T. carboxydivorans Park et al. 2009 (Park et al., 2009) as a later heterotypic synonym of T. tyrosinosolvens Yassin et al. 1997 (Yassin et al., 1997), and T. sunchonensis Seong et al. 2008 (Seong et al., 2003) as a later heterotypic synonym of T. pseudospumae Nam et al. 2004 (Nam et al., 2004), respectively. With the decreasing costs of high-throughput sequencing genomic data may be considered as one of the taxonomic criteria for species delineation of bacteria, especially in the case where two strains share highly similar phenotypic characteristics and 16S rRNA gene sequences.

\section{Emended Description of T. pulmonis Yassin et al. 1996 (Yassin et al., 1996)}

Tsukamurella pulmonis (pul. mo' nis. L. gen. masc. n. pulmonis, of the lung, referring to the organ from which the bacterium was isolated).

\section{Heterotypic Synonym: T. spongiae Olson et al. 2007 (Olson et al., 2007)}

The characteristics of T. pulmonis are described by Yassin et al. (1996), with the following amendments. Grows best on Columbia agar with $5 \%$ defibrinated sheep blood agar as white or orange to red and rough or easily emulsified colonies, $2 \mathrm{~mm}$ in diameter, with irregular spreading margins after $48 \mathrm{~h}$ of incubation at $25^{\circ} \mathrm{C}$ under aerobic conditions. As determined by API $50 \mathrm{CH}$ kit, cells are able to assimilate glycerol, D-arabinose, D-galactose, D-glucose, D-fructose, Dmannitol, D-sorbitol, $N$-acetyl glucosamine, esculin ferric citrate, D-saccharose, D-trehalose, D-turanose, L-fucose, D-arabitol, and potassium gluconate. The major fatty acids ( $>10 \%$ of the total) are $\mathrm{C}_{16: 0}, \mathrm{C}_{18: 1 \omega 9 c}, 10$-methyl $\mathrm{C}_{18: 0}$ and summed feature 1 $\left(\mathrm{C}_{16: 1 \omega 6 c}\right.$ and/or $\mathrm{C}_{16: 1 \omega 7 c}$ and/or iso- $\left.\mathrm{C}_{15: 0} 2-\mathrm{OH}\right)$.

The type strain, CCUG $35732^{\mathrm{T}}\left(=\mathrm{JCM} 10111^{\mathrm{T}}=\mathrm{DSM}\right.$ $44142^{\mathrm{T}}$ ), was isolated from human with mycobacterial lung infection. The $\mathrm{G}+\mathrm{C}$ content of the type strain is $70.4 \mathrm{~mol} \%$. The reference strain, DSM 44990 (=JCM 14882), is the nomenclatural type of T. spongiae Olson et al. 2007 (Olson et al., 2007), and was isolated from a deep-water marine sponge. The $\mathrm{G}+\mathrm{C}$ content of strain DSM 44990 is $71.1 \mathrm{~mol} \%$. The GenBank accession numbers of whole genome sequence of the type strain and reference strain are LSRH00000000.1 and LSRI00000000.1, respectively.

\section{Emended Description of T. tyrosinosolvens Yassin et al. 1997 (Yassin et al., 1997)}

Tsukamurella tyrosinosolvens (ty. ro. si. no. sol' vens. Gr. masc. n. tyros, cheese; tyrosine, an amino acid; L. pres. part. solvens, dissolving; M.L. adj. tyrosinoslovens, tyrosine dissolving, referring to the hydrolysis of tyrosine which is characteristics of this species.

Heterotypic Synonym: T. carboxydivorans Park et al. 2009 (Park et al., 2009)

The characteristics of T. tyrosinosolvens are described by Yassin et al. (1997), with the following amendments. As determined by API $50 \mathrm{CH}$ kit, cells are capable of assimilating glycerol,
D-arabinose, D-ribose, D-galactose, D-glucose, D-fructose, D-mannose, myo-inositol, D-mannitol, D-sorbitol, methyl-Dglucopyranoside, $\mathrm{N}$-acetyl glucosamine, arbutin, esculin ferric citrate, D-maltose, D-saccharose, D-trehalose, D-melezitose, xylitol, D-turanose, L-fucose, D-arabitol, potassium gluconate, and 2-ketogluconate. The major fatty acids ( $>10 \%$ of the total) are $\mathrm{C}_{16: 0}, \mathrm{C}_{18: 1 \omega 9 c}, 10$-methyl $\mathrm{C}_{18: 0}$ and summed feature 1 $\left(\mathrm{C}_{16: 1 \omega 6 c}\right.$ and/or $\mathrm{C}_{16: 1 \omega 7 c}$ and/or iso- $\left.\mathrm{C}_{15: 0} 2-\mathrm{OH}\right)$.

The type strain, CCUG $38499^{\mathrm{T}}\left(=\mathrm{JCM} 10112^{\mathrm{T}}=\mathrm{DSM}\right.$ $44234^{\mathrm{T}}$ ), was isolated from blood culture of a patient with cardiac pacemaker implants. The $\mathrm{G}+\mathrm{C}$ content of the type strain is $71.2 \mathrm{~mol} \%$. The reference stain, JCM 15482 (=KCCM 52885), is the nomenclatural type of T. carboxydivorans Park et al. 2009 (Park et al., 2009), and was isolated from soil sample from a roadside. The G+C content of strain JCM 15482 is $71.2 \mathrm{~mol} \%$. The GenBank accession numbers of whole genome sequence of the type strain and reference strain are LSRJ00000000.1 and LSRG00000000.1, respectively.

\section{Emended Description of T. pseudospumae Nam et al. 2004 (Nam et al., 2004)}

Tsukamurella pseudospumae (pseu.do.spu'mae. Gr. adj. pseudes false; L. gen. n. spumae of foam and specific epithet of bacterial species; N. L. n. pseudospumae the false spumae, referring to the close relationship to Tsukamurella spumae).

\section{Heterotypic Synonym: T. sunchonensis Seong et al. 2008 (Seong et al., 2003)}

The characteristics of T. pseudospumae are described by Nam et al. (2004), with the following amendments. As determined by API $50 \mathrm{CH}$ kit, cells are capable to grow on brain-heart infusion agar. Positive for hydrolysis of tyrosine. Assimilates glycerol, D-ribose, D-galactose, D-glucose, D-fructose, D-mannose, methylD-glucopyranoside, $N$-acetyl glucosamine, esculin ferric citrate, D-maltose, D-saccharose, D-trehalose, D-melezitose, D-turanose, and potassium gluconate. The major fatty acids $(>10 \%$ of the total) are $\mathrm{C}_{16: 0}, \mathrm{C}_{18: 1 \omega 9 c}, 10$-methyl $\mathrm{C}_{18: 0}$ and summed feature 1 $\left(\mathrm{C}_{16: 1 \omega 6 c}\right.$ and/or $\mathrm{C}_{16: 1 \omega 7 c}$ and/or iso- $\left.\mathrm{C}_{15: 0} 2-\mathrm{OH}\right)$.

The type strain, JCM $13375^{\mathrm{T}}\left(=\mathrm{DSM} 44118^{\mathrm{T}}\right)$, was isolated from extensive foam in the aeration basin of an activated sludge process. The $\mathrm{G}+\mathrm{C}$ content of the type strain is $70.6 \mathrm{~mol} \%$. The reference strain, JCM 15929 (=NRRL B-24668), is the nomenclatural type of T. sunchonensis Seong et al. 2008 (Seong et al., 2003), and was also isolated from activated sludge foam. The $\mathrm{G}+\mathrm{C}$ content of strain JCM 15929 is 70.5 mol\%. The GenBank accession numbers of whole genome sequence of the type strain and reference strain are LSRF00000000.1 and LSRE00000000.1, respectively.

\section{DATA ACCESSIBILITY}

This Whole Genome Shotgun project has been deposited in DDBJ/ENA/GenBank under the accession numbers LSRE00000000-LSRJ00000000. The version described in 
this paper is version LSRE00000000.1-LSRJ00000000.1. The GenBank accession numbers for the draft genome sequences of Tsukamurella pseudospumae JCM $13375^{\mathrm{T}}$, Tsukamurella sunchonensis JCM $15929^{\mathrm{T}}$, Tsukamurella carboxydivorans JCM $15482^{\mathrm{T}}$, Tsukamurella pulmonis CCUG $35732^{\mathrm{T}}$, Tsukamurella spongiae DSM $44990^{\mathrm{T}}$ and Tsukamurella tyrosinosolvens CCUG $38499^{\mathrm{T}}$ are LSRE00000000.1, LSRF00000000.1, LSRG00000000.1, LSRH00000000.1, LSRI00000000.1, and LSRJ00000000.1, respectively.

\section{AUTHOR CONTRIBUTIONS}

JT conceived of the study, designed the study, carried out the molecular lab work, participated in data analysis, and drafted the manuscript; YT carried out the molecular lab work, participated in data analysis, and helped draft the manuscript. YH, F-BG, WW, and JC participated in data analysis; SW contributed reagents; SL revised the manuscript and contributed reagents; PW conceived of the study, designed the study, contributed

\section{REFERENCES}

Abràmoff, M. D., Magalhaes, P. J., and Ram, S. J. (2004). Image processing with ImageJ. Biophotonics Int. 11, 36-42.

Almehmi, A., Pfister, A. K., McCowan, R., and Matulis, S. (2004). Implantable cardioverter-defibrillator infection caused by Tsukamurella. W. V. Med. J. 100, $185-186$.

Auch, A. F., Klenk, H. P., and Göker, M. (2010). Standard operating procedure for calculating genome-to-genome distances based on high-scoring segment pairs. Stand. Genomic Sci. 2, 142-148.doi: 10.4056/sigs.541628

Aziz, R. K., Bartels, D., Best, A. A., DeJongh, M., Disz, T., Edwards, R. A., et al. (2008). The RAST Server: rapid annotations using subsystems technology. BMC Genomics 9:75.doi: 10.1186/1471-2164-9-75

Bouza, E., Pérez-Parra, A., Rosal, M., Martín-Rabadán, P., RodríguezCréixems, M., and Marín, M. (2009). Tsukamurella: a cause of catheter-related bloodstream infections. Eur. J. Clin. Microbiol. Infect. Dis. 28, 203-210.doi: 10.1007/s10096-008-0607-2

Collins, M. D., Goodfellow, M., and Minnikin, D. E. (1982). A survey of the structures of mycolic acids in Corynebacterium and related taxa. J. Gen. Microbiol. 128, 129-149. doi: 10.1099/00221287-128-1-129

Collins, M. D., and Jones, D. (1982). Lipid composition of Corynebacterium paurometabolum (Steinhaus). FEMS Microbiol. Lett. 13, 13-16. doi: 10.1111/j.1574-6968.1982.tb08217.x

Collins, M. D., Smida, J., Dorsch, M., and Stackebrandt, E. (1988). Tsukamurella gen. nov., harboring Corynebacterium paurometabolum and Rhodococcus aurantiacus. Int. J. Syst. Bacteriol. 38, 385-391.doi: 10.1099/0020771338-4-385

Conville, P. S., and Witebsky, F. G. (2007). "Nocardia, Rhodococcus, Gordonia, Actinomadura, Streptomyces, and other aerobic actinomycetes," in Manual of Clinical Microbiology, 9th Edn, eds P. R. Murray, E. J. Baron, J. H. Jorgensen, M. R. Louise, and M. A. Pfaller (Washington, DC: American Society for Microbiology), 515-542.

Delcher, A. L., Bratke, K. A., Powers, E. C., and Salzberg, S. L. (2007). Identifying bacterialgenes and endosymbiont DNA with Glimmer. Bioinformatics 23, 673679.doi: 10.1093/bioinformatics/btm009

Euzéby, J. (2008). Validation List 123. Int. J. Syst. Evol. Microbiol. 58, 1993-1994.

Fox, G. E., Magrum, L. J., Balch, W. E., Wolfe, R. S., and Woese, C. R. (1977). Classification of methanogenic bacteria by $16 \mathrm{~S}$ ribosomal RNA characterization. Proc. Natl. Acad. Sci. U.S.A. 74, 4537-4541.doi: 10.1073/pnas.74.10.4537

Goodfellow, M., and Kumar, Y. (2012). "Genus I. Tsukamurella Collins, Smida, Dorsch and Stackebrandt 1988, 387," in Bergey's Mannual of Systematic reagents, and drafted the manuscript. All authors gave final approval for publication.

\section{FUNDING}

This work was partly supported by the Strategic Research Theme Fund and the Small Project Funding Scheme, The University of Hong Kong.

\section{ACKNOWLEDGMENTS}

Pertinent taxonomic information was accessed through the "Names for Life" online tool (http://www.namesforlife.com). We thank Dr. Rüdiger Pukall of DSMZ and Dr. Takuji Kudo of JCM for clarifying the colony morphology of T. spongiae DSM $44990^{\mathrm{T}}$ and T. carboxydivorans JCM $15482^{\mathrm{T}}$. We also thank members of the Centre for Genomic Sciences, The University of Hong Kong, for their technical support in genome sequencing.

Bacteriology, 2nd Edn, eds M. Goodfellow, P. Kämpfer, H.-J. Busse, M. E. Trujillo, K.-I. Suzuki, W. Ludwig et al. (New York, NY: Springer), 500-509.

Goris, J., Konstantinidis, K. T., Klappenbach, J. A., Coenye, T., Vandamme, P., and Tiedje, J. M. (2007). DNA-DNA hybridization values and their relationship to whole-genome sequence similarities. Int. J. Syst. Evol. Microbiol. 57, 81-91.doi: 10.1099/ijs.0.64483-0

Gupta, R., Lanter, J. M., and Woese, C. R. (1983). Sequence of the 16 S ribosomal RNA from Halobacterium volcanii, an archaebacterium. Science 221, 656659.doi: 10.1126/science.221.4611.656

Hall, T. A. (1999). BioEdit: a user-friendly biological sequence alignment editor and analysis program for Windows 95/98/NT. Nucleic Acids Symp. Ser. 41, 95-98.

Jiang, Y., Chen, X., Han, L., Li, Q., Huang, X., Qiu, S. M., et al. (2013). Diversity of cultivable actinomycetes in 6 species of herbivore feces. Int. J. Microbiol. Res. 1, 76-84.

Kattar, M. M., Cookson, B. T., Carlson, L. D., Stiglich, S. K., Schwartz, M. A., Nguyen, T. T., et al. (2001). Tsukamurella strandjordae sp. nov., a proposed new species causing sepsis. J. Clin. Microbiol. 39, 1467-1476.doi: 10.1128/JCM.39.4.1467-1476.2001

Ketterlinus, R., Hsieh, S. Y., Teng, S. H., Lee, H., and Pusch, W. (2005). Fishing for biomarkers: analyzing mass spectrometry data with the new ClinProTools software. Biotechniques 38(Suppl. 6), 37-40. doi: 10.2144/05386SU07

Konstantinidis, K. T., and Tiedje, J. M. (2005). Genomic insights that advance the species definition for prokaryotes. Proc. Natl. Acad. Sci. U.S.A. 102, 25672572.doi: 10.1073/pnas.0409727102

Lapage, S. P., Sneath, P. H. A., Lessel, E. F., Skerman, V. B. D., Seeliger, H. P. R., and Clark, W. A. (eds) (1992). International Code of Nomenclature of Bacteria (1990 Revision). Bacteriological Code. Washington, DC: American Society for Microbiology.

Larkin, J. A., Lit, L., Sinnott, J., Wills, T., and Szentivanyi, A. (1999). Infection of aknee prosthesis with Tsukamurella species. South. Med. J. 92, 831-832.doi: 10.1097/00007611-199908000-00019

Lau, S. K., Tang, B. S., Teng, J. L., Chan, T. M., Curreem, S. O., Fan, R. Y., et al. (2014). Matrix-assisted laser desorption ionization time-of-flight mass spectrometry for identification of clinically significant bacteria that are difficult to identify in clinical laboratories. J. Clin. Pathol. 67, 361-366.doi: 10.1136/jclinpath-2013-201818

Liu, C. Y., Lai, C. C., Lee, M. R., Lee, Y. C., Huang, Y. T., Liao, C. H., et al. (2011). Clinical characteristics of infections caused by Tsukamurella spp. and antimicrobial susceptibilities of the isolates. Int. J. Antimicrob. Agents 38, 534-537.doi: 10.1016/j.ijantimicag.2011.07.018

Maeda, Y., Stanley, T., Stirling, J., Griffiths, M., Calvert, A., Stuart Elborn, J., et al. (2010). No evidence of transmission of bacteria between reptiles and a CF 
patient-a case report of a young adult CF patient and reptiles. Zoonoses Public Health 57:e47-e53.doi: 10.1111/j.1863-2378.2009.01293.x

Nam, S. W., Kim, W., Chun, J., and Goodfellow, M. (2004). Tsukamurella pseudospumae sp. nov., a novel actinomycete isolated from activated sludge foam. Int. J. Syst. Evol. Microbiol. 54, 1209-1212.doi: 10.1099/ijs.0.02939-0

Olson, J. B., Harmody, D. K., Bej, A. K., and McCarthy, P. J. (2007). Tsukamurella spongiae sp. nov., a novel actinomycete isolated from a deep-water marine sponge. Int. J. Syst. Evol. Microbiol. 57, 1478-1481.doi: 10.1099/ijs.0.64837-0

Palys, T., Nakamura, L. K., and Cohan, F. M. (1997). Discovery and classification of ecological diversity in the bacterial world: the role of DNA sequence data. Int. J. Syst. Bacteriol. 47, 1145-1156.doi: 10.1099/00207713-47-4-1145

Park, S. W., Kim, S. M., Park, S. T., and Kim, Y. M. (2009). Tsukamurella carboxydivorans sp. nov., a carbon monoxide-oxidizing actinomycete. Int. J. Syst. Evol. Microbiol. 59, 1541-1544. doi: 10.1099/ijs.0.005959-0

Richter, M., and Rosselló-Móra, R. (2009). Shifting the genomic gold standard for the prokaryotic species definition. Proc. Natl. Acad. Sci. U.S.A. 106, 1912619131.doi: 10.1073/pnas.0906412106

Sasser, M. (1990). "Identification of bacteria through fatty acid analysis", in Methods in Phytobacteriology, eds Z. Klement, K. Rudolph and D. C. Sands (Budapest: Akademiai Kiado), 199-204.

Schwartz, M. A., Tabet, S. R., Collier, A. C., Wallis, C. K., Carlson, L. C., Nguyen, T. T., et al. (2002). Central venous catheter-related bacteremia due to Tsukamurella species in the immunocompromised host: a case series and review of the literature. Clin. Infect. Dis. 35:e72-e77.doi: 10.1099/ijs.0.00 5959-0

Seong, C. N., Kim, Y. S., Baik, K. S., Goodfellow, M., et al. (2003). Tsukamurella sunchonensis sp. nov., a bacterium associated with foam in activated sludge. J. Microbiol. 41, 83-88.

Shaer, A. J., and Gadegbeku, C. A. (2001). Tsukamurella peritonitis associated with continuous ambulatory peritoneal dialysis. Clin. Nephrol. 56, 241-246.

Stackebrandt, E., and Goebel, B. M. (1994). Taxonomic note: a place for DNA-DNA reassociation and $16 \mathrm{~S}$ rRNA sequence analysis in the present species definition in bacteriology. Int. J. Syst. Bacteriol. 44, 846-849.doi: 10.1099/00207713-444-846

Steinhaus, E. A. (1941). A study of the bacteria associated with thirty species of insects. J. Bacteriol. 42, 757-790.

Tamura, K., Stecher, G., Peterson, D., Filipski, A., and Kumar, S. (2013). MEGA6: molecular evolutionary genetics analysis version 6.0. Mol. Biol. Evol. 30, 2725 2729.doi: 10.1093/molbev/mst197

Teng, J. L., Huang, Y., Tse, H., Chen, J. H., Tang, Y., Lau, S. K., et al. (2014). Phylogenomic and MALDI-TOF MS analysis of Streptococcus sinensis HKU4T reveals a distinct phylogenetic clade in the genus Streptococcus. Genome Biol. Evol. 6, 2930-2943.doi: 10.1093/gbe/evu232

Teng, J. L., Tang, Y., Wong, S. S., Ngan, A. H., Huang, Y., Tsang, C. C., et al. (2015). Tsukamurella hongkongensis sp. nov. and Tsukamurella sinensis sp. nov. isolated from patients with keratitis, catheter-related bacteraemia and conjunctivitis in Hong Kong. Int. J. Syst. Bacteriol. 66, 391-397.doi: 10.1099/ijsem.0.000733

Tse, H., Tsoi, H. W., Leung, S. P., Lau, S. K., Woo, P. C., and Yuen, K. Y. (2010). Complete genome sequence of Staphylococcus lugdunensis strain HKU09-01. J. Bacteriol. 192, 1471-1472.doi: 10.1128/JB.01627-09
Verroken, A., Janssens, M., Berhin, C., Bogaerts, P., Huang, T. D., Wauters, G., et al. (2010). Evaluation of matrix-assisted laser desorption ionization-time of flight mass spectrometry for identification of Nocardia species. J. Clin. Microbiol. 48, 4015-4021.doi: 10.1128/JCM.01234-10

Wayne, L. G. (1988). International Committee on Systematic Bacteriology: announcement of the report of the ad hoc Committee on Reconciliation of Approaches to Bacterial Systematics. Zentralbl. Bakteriol. Mikrobiol. Hyg. A 268, 433-434.doi: 10.1016/S0176-6724(88)80120-2

Wei, W., Gao, F., Du, M. Z., Hua, H. L., Wang, J., and Guo, F. B. (2016). Zisland Explorer: detect genomic islands by combining homogeneity and heterogeneity properties. Brief. Bioinform.doi: 10.1093/bib/bbw019 [Epub ahead of print].

Wei, W., and Guo, F. B. (2011). Prediction of genomic islands in seven human pathogens using the Z-Island method. Genet. Mol. Res. 10, 2307-2315.doi: 10.4238/2011.October.5.1

Woo, P. C., Lau, S. K., Teng, J. L., Tse, H., and Yuen, K. Y. (2008). Then and now: use of $16 \mathrm{~S}$ rDNA gene sequencing for bacterial identification and discovery of novel bacteria in clinical microbiology laboratories. Eur. J. Clin. Microbiol. Infect. Dis. 14, 908-934.doi: 10.1111/j.1469-0691.2008. 02070.x

Woo, P. C., Lau, S. K., Tse, H., Teng, J. L., Curreem, S. O., Tsang, A. K., et al. (2009). The complete genome and proteome of Laribacter hongkongensis reveal potential mechanisms for adaptations to different temperatures and habitats. PLoS. Genet. 5:e1000416.doi: 10.1371/journal.pgen.10 00416

Woo, P. C., Ngan, A. H., Lau, S. K., and Yuen, K. Y. (2003). Tsukamurella conjunctivitis: a novel clinical syndrome. J. Clin. Microbiol. 41, 3368-3371.doi: 10.1128/JCM.41.7.3368-3371.2003

Woo, P. C., Wu, A. K., Tsang, C. C., Leung, K. W., Ngan, A. H., Curreem, S. O., et al. (2014). Streptobacillus hongkongensis sp. nov., isolated from patients with quinsy and septic arthritis, and emended descriptions of the genus Streptobacillus and Streptobacillus moniliformis. Int. J. Syst. Bacteriol. 64, 3034-3039.doi: 10.1099/ijs.0.061242-0

Yassin, A. F., Rainey, F. A., Brzezinka, H., Burghardt, J., Rifai, M., Seifert, P., et al. (1996). Tsukamurella pulmonis sp. nov. Int. J. Syst. Bacteriol. 46, 429-436. doi: 10.1099/00207713-46-2-429

Yassin, A. F., Rainey, F. A., Burghardt, J., Brzezinka, H., Schmitt, S., Seifert, P., et al. (1997). Tsukamurella tyrosinosolvens sp. nov. Int. J. Syst. Bacteriol. 47, 607-614. doi: 10.1099/00207713-47-3-607

Conflict of Interest Statement: The authors declare that the research was conducted in the absence of any commercial or financial relationships that could be construed as a potential conflict of interest.

Copyright (c) 2016 Teng, Tang, Huang, Guo, Wei, Chen, Wong, Lau and Woo. This is an open-access article distributed under the terms of the Creative Commons Attribution License (CC BY). The use, distribution or reproduction in other forums is permitted, provided the original author(s) or licensor are credited and that the original publication in this journal is cited, in accordance with accepted academic practice. No use, distribution or reproduction is permitted which does not comply with these terms. 